\title{
Cloning and Characterization of $\delta$-Guaiene Synthase Genes Encoding a Sesquiterpene Cyclase from Aquilaria microcarpa Cell Cultures
}

\author{
Fumiya Kurosaki, Syun Hirohashi, Takahiro Katoh, Futoshi Taura, Jung-Bum Lee \\ Laboratory of Medicinal Bio-Resources, Graduate School of Medicine and Pharmaceutical Sciences for \\ Research, University of Toyama, Sugitani, Toyama, Japan \\ Email: kurosaki@pha.u-toyama.ac.jp
}

Received 4 September 2015; accepted 20 October 2015; published 23 October 2015

Copyright @ 2015 by authors and Scientific Research Publishing Inc.

This work is licensed under the Creative Commons Attribution International License (CC BY). http://creativecommons.org/licenses/by/4.0/

(c) (i) Open Access

\section{Abstract}

Three cDNA clones encoding $\delta$-guaiene synthase, a sesquiterpene cyclase, were isolated from tissue cultures of Aquilaria microcarpa, and data mining analysis of the orthologous genes suggested that 10 and 9 amino acid residues of $\mathrm{N}$ - and $\mathrm{C}$-terminal ends of the translated products of these clones remained undefined. The recombinant enzyme proteins, to which the putative missing $\mathrm{N}$ and C-terminal amino acid sequences (MSSAKLGSAS and ALLRHAIEI, respectively) were ligated, exhibited the catalytic activities of sesquiterpene biosynthesis. Among these three $\delta$-guaiene synthases, two isoforms were capable of liberating $\alpha$-guaiene, $\delta$-guaiene, $\beta$-elemene plus $\alpha$-humulene as a minor product, while remaining one isoenzyme generated $\alpha$-, $\delta$-guaiene and $\beta$-elemene but not $\alpha$-humulene. Although the enzyme protein solely lacking in the $\mathrm{N}$-terminal $\mathbf{1 0}$ amino acid residues was capable of synthesizing the sesquiterpenoids, the protein without 9 amino acids at Cterminal did not exhibit the catalytic activity. These results suggest that two types of $\delta$-guaiene synthase; $\alpha$-, $\delta$-guaiene, $\beta$-elemene-producing type, and $\alpha$-, $\delta$-guaiene, $\beta$-elemene plus $\alpha$-humulene-producing type; concomitantly occur in $A$. microcarpa cell cultures, and several amino acid residues at C-terminal of the synthase protein are essential to exhibit the catalytic activities as the sesquiterpene cyclase.

\section{Keywords}

Methyl Jasmonate, Yeast Extract, Sesquiterpene, $\delta$-Guaiene Synthase, Aquilaria microcarpa 


\section{Introduction}

It has been widely known [1] that Aquilaria, and Gyrinops species sometimes form dark resinous heartwood, called agarwood, in the trunk of the plants in response to mechanical wounding or microbial infection. Agarwood produces a variety of sesquiterpene compounds with aroma, and, therefore, it has been used as the scent, perfume and traditional medicines [1]. These highly valuable tissues are not formed under healthy conditions, and artificial transformation of these trees to agarwood has been very difficult. Okudera and Ito, however, reported [2] that biosynthetic activities of several sesquiterpenoids, such as $\delta$-guaiene, $\alpha$-guaiene and $\alpha$-humulene, are induced in cell cultures of $A$. crassna by the treatment with methyl jasmonate or yeast extract. Guaianolide sesquiterpene compounds are thought to be synthesized via two cyclization reactions [3]: i) C1-to-C10 cyclization generating germacrene-like macrocyclic intermediate; and ii) C2-to-C6 cyclization forming guaiane-skeleton (Figure 1). A part of the macrocyclic intermediate is converted to $\alpha$-humulene or germacrene A without the second cyclization. It has been also demonstrated [4] [5] that $\beta$-elemene is an artificially formed compound by the pyrolysis of germecrene A. Recently, several cDNA clones encoding $\delta$-guaiene synthase, a sesquiterpene cyclase, have been isolated from A. crassna and A. sinensis [3] [6]. Catalytic specificities of the translated proteins of these genes have been extensively studied, and it has been shown that the enzymes liberate multiple sesquiterpene compounds, such as $\delta$-guaiene, $\alpha$-guaiene, $\beta$-elemene and $\alpha$-humulene, from farnesyl diphosphate as the substrate. However, only very little is known about the molecular basis of the enzymatic reaction of the synthase generating multiple products.

We have recently shown [5] [7] that treatment of cell cultures of A. microcarpa with methyl jasmonate or yeast extract results in the marked transcriptional activation of $\delta$-guaiene synthase gene, and a cDNA clone (GS-1, GenBank accession No. KF800046) encoding the enzyme protein has been isolated [5]. It has been also demonstrated that GS-1 translate catalyzes the formation of $\delta$-guaiene, $\alpha$-guaiene and $\beta$-elemene, but not $\alpha$-humulene [5]. In the present experiments, we have isolated three additional clones of the synthase gene although several amino acid residues at both $\mathrm{N}$ - and C-terminal ends of the translated proteins remain undefined. In order to understand the inducible biosynthetic activities of A. microcarpa liberating multiple sesquiterpene compounds, we have ligated putative missing amino acid sequences to $\mathrm{N}$ - and C-terminals of the recombinant proteins, and examined the catalytic properties of these 'deficiencies supplied' $\delta$-guaiene synthases.

\section{Materials and Methods}

\subsection{Cloning of $\delta$-Guaiene Synthase Genes from A. microcarpa Cell Culture}

Seeds of A. microcarpa were generous gift from Professor Shigetoshi Kadota, Institute of Natural Medicine, University of Toyama, and they were germinated and grown in a greenhouse at Experimental Station for Medi-

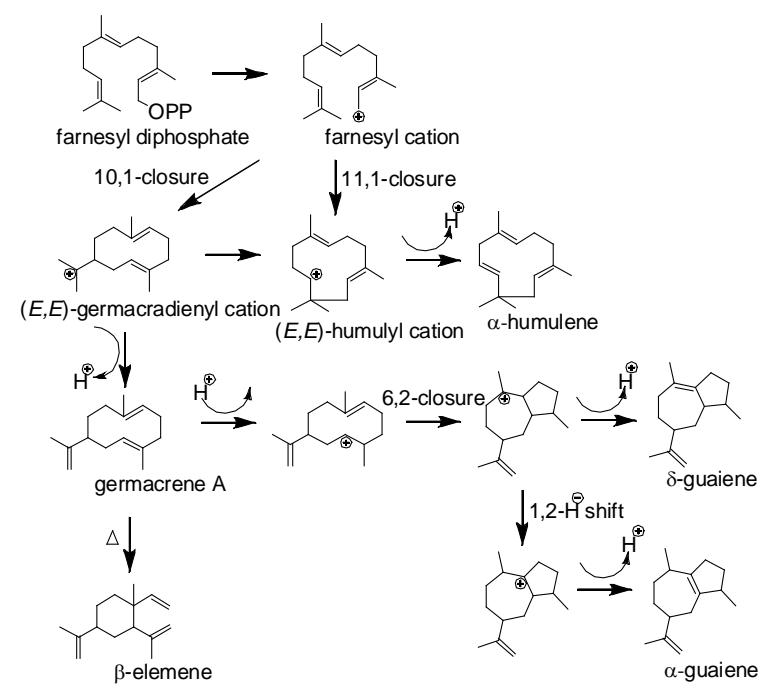

Figure 1. Predicted biosynthetic pathway of sesquiterpene compounds of Aquilaria plants. 
cinal Plant Research of our university. Sterilized young leaf tissues of the plant were placed on Murashige and Skoog's agar medium [8] supplemented with $3 \%$ (w/v) sucrose and $3 \mu \mathrm{M}$ of 2,4-dichlorophenoxyacetic acid, and callus formation was observed in the leaf veins after 4 weeks. The dedifferentiated cells were then incubated on the medium in the presence of $3 \mu \mathrm{M}$ of 2,4-dichlorophenoxyacetic acid and $3 \mu \mathrm{M}$ of $\mathrm{N}^{6}$-benzyladenine at $26^{\circ} \mathrm{C}$ under darkness. After establishment of the callus culture, the cells were transferred onto a fresh medium every 3 weeks as described previously in detail [9] [10]. Total RNA was isolated from yeast extract-treated cultured cells (approximately $100 \mathrm{mg}$ ) with RNeasy Plant Mini Kit (Qiagen, Hilden, Germany) [5] [9], and cDNA templates were generated by reverse transcription reaction using Transcriptor First Strand cDNA Synthesis Kit (Roche, Basel, Switzerland). The cDNA fragments presumably encoding the translatable region of $\delta$-guaiene synthase were isolated by PCR amplification employing the primer pair designated from the nucleotide sequence of the homologous gene previously isolated [5] (5'-ATG TCT TCG GCA AAA CTA GGT TCT GCC TCC-3' as the forward and 5'-TCA GAT TTC AAT AGC ATG ACG CAA CAA GGC-3' as the reverse primer). The amplified cDNAs were subcloned into the pGEM-T Easy vector (Promega, Fitchburg, WI, USA), and the nucleotide sequences were determined on both strands using the dye-terminator method on a PRISM $3130 \mathrm{Ge}$ netic Analyzer (Applied Biosystems, Waltham, MA, USA).

\subsection{Preparation and Purification of Recombinant $\delta$-Guaiene Synthase Proteins}

The modified $\delta$-guaiene synthase genes, GS-2, 3 and 4, in which undefined sequences of the translatable regions were ligated, were amplified using a common primer pair (5'-ATG TCT TCG GCA AAA CTA GGT TCT GCC TCC-3' as the forward and 5'-TCA GAT TTC AAT AGC ATG ACG CAA CAA GGC-3' as the reverse primer, 1644 mer as the product). Amplification of $G S-2 \triangle N \Delta C$, the undefined regions-omitted gene, was performed with 5'-GAA GAT GTT AGC CGC CGA GAT GCC-3' as the common forward primer and 5'-TCA GGC AAT TCT ATC CTT GGT CAC-3' as the gene specific reverse primer employing pGEM-T Easy vector harboring GS-2 as the template. GS-3 $\triangle N \Delta C$ and $G S-4 \Delta N \Delta C$ were similarly amplified by the combination of the common forward primer and the gene specific reverse primer (5'-TCA GGC AAT TCT ACC CTT GGT CAC-3' for GS-3 $\triangle N \Delta C$, and 5'-TCA GGC AAT TCT ATC TTT GGT CAC-3' for GS-4 $\triangle N \Delta C$, respectively). GS-4 $\triangle N$ and $G S-4 \triangle C$ were also amplified by the appropriate combinations of the common primer and the specific primers (5'-GAA GAT GTT AGC CGC CGA GAT GCC-3' and 5'-TCA GAT TTC AAT AGC ATG ACG CAA CAA GGC-3' for GS-4AN while 5'-ATG TCT TCG GCA AAA CTA GGT TCT GCC TCC-3' and 5'-TCA GGC AAT TCT ATC TTT GGT CAC-3' for GS-4AC) using GS-4 subcloned into pGEM-T Easy vector as the template.

Over expression of $\delta$-guaiene synthase genes in Escherichia coli was performed using the E. coli Expression System with Gateway Technology (Invitrogen, Waltham, MA, USA). Desired regions of the synthase genes amplified by PCR were successively subcloned into pENTR and pDEST15 (Invitrogen, Waltham, MA, USA), and then, E. coli BL21 cells were transformed with the constructed expression vectors. The cell cultures were grown in LB medium overnight at $25^{\circ} \mathrm{C}$, and, after transfer into the fresh medium, isopropyl $\beta$-D-1-thiogalactopyranoside (IPTG, final concentration $0.1 \mathrm{mM}$ ) was added to the cultures at an optical density of $0.4-0.5$ at $600 \mathrm{~nm}$. The cultures were further incubated at $25^{\circ} \mathrm{C}$ for $5 \mathrm{~h}$. $\delta$-Guaiene synthase proteins were recovered as the glutathione-S-transferase (GST) tagged form, and were purified by an affinity chromatography on a Glutathione-Sepharose 4B column (GE Healthcare Life Sciences, Little Chalfont, UK) according to the instruction manual. Protein concentrations were determined by the method of Bradford [11], and, if necessary, the purified enzyme solutions were appropriately concentrated by Amicon Ultra-15 (Merck Millipore, Billerica, MA, USA). The samples were, then, subjected to sodium dodecyl sulfate polyacrylamide gel electrophoresis (SDS-PAGE, $10 \%$ gel) according to the method of Laemmli [12], and the separated proteins were stained with Coomassie brilliant blue.

\subsection{Catalytic Activities of Recombinant $\delta$-Guaiene Synthase Proteins}

In order to examine sesquiterpene biosynthetic activities of the recombinant $\delta$-guaiene synthases, the purified enzyme proteins were incubated with farnesyl diphosphate as the substrate, and the reaction products were analyzed by GC-MS. The assay mixtures (200 $\mu \mathrm{l}$ ) contained $50 \mathrm{mM}$ Tris-HCl (pH 7.0), $20 \mathrm{mM} \mathrm{MgCl}$, $10 \mathrm{mM}$ dithiothreitol, $46 \mu \mathrm{M}$ farnesyl diphosphate (Sigma-Aldrich, St. Louis, MO, USA), 10\% (v/v) glycerol, purified GST- $\delta$-guaiene synthase proteins (approximately $10 \mu \mathrm{g})$ and limonene $(0.2 \mu \mathrm{g}$, nacalai tesque, Kyoto, Japan) as 
an internal standard. In a control experiment, the enzyme proteins were heat denatured $\left(95^{\circ} \mathrm{C}, 10 \mathrm{~min}\right)$ prior to the assay. The mixtures were incubated at $25^{\circ} \mathrm{C}$ for $4 \mathrm{~h}$, and the reaction products were extracted using headspace solid phase microextraction assembly with a $100 \mu \mathrm{m}$ polydimethylsiloxane fiber (Supelco, Bellefonte, PA, USA). The fiber was exposed to the sample headspace for $30 \mathrm{~min}$, and, after adsorption of the reaction products, sesquiterpene compounds were analyzed by GC-MS (Shimadzu, GCMS-QP5000; Agilent, J\&W DB-1ms 0.32 $\mathrm{mm} \times 30 \mathrm{~m}$ column) in the splitless mode. The injection port and the interface temperature were adjusted at $250^{\circ} \mathrm{C}$, and the mass range was set from $\mathrm{m} / \mathrm{z} 40$ to 400 . The carrier flow (He) was at $1.4 \mathrm{ml} / \mathrm{min}$. The oven temperature was started at $50^{\circ} \mathrm{C}$ for 2 min and was increased to $170^{\circ} \mathrm{C}$ at the rate of $4^{\circ} \mathrm{C} / \mathrm{min}$, then raised to $300^{\circ} \mathrm{C}$ at $30^{\circ} \mathrm{C} / \mathrm{min}$. The reaction products were separated under the above conditions to calculate retention indices, and the identification of the compounds was based on the comparison of reported retention indices [13] [14] and mass spectra with those in the NIST02 and Wiley 7 MS databases.

\section{Results}

\section{1. $\delta$-Guaiene Synthase Genes of $A$. microcarpa Cell Culture}

It has been demonstrated [3] [6] that sesuqiterpene biosynthetic genes encoding $\delta$-guaiene synthase in Aquilaria plants are usually organized as the multigene family. To our knowledge, seven orthologues of the synthase genes have been isolated from Aquilaria plants (A. crassna, A. sinensis and A. microcarpa), and the translated products of these genes are found to be highly conserved. All of the synthase proteins consist of 547 amino acid residues and the sequences also show very high homology (98\% - 99\% identity) [3] [5] [6]. In order to isolate $\delta$-guaiene synthase genes other than GS-1 from A. microcarpa cell cultures, we employed the primer pair corresponding to the $\mathrm{N}$ - and C-terminal ends of the translatable region of GS-1 (30 nucleotides each, including stop codon for C-terminal). Three new clones presumably encoding $\delta$-guaiene synthase were isolated (GS-2 $\Delta N \Delta C$, GS-3 $\triangle N \Delta C$ and GS-4AN $\Delta C$; GenBank accession No. KT283579, KT283580 and KT283581, respectively), and the putative amino acid sequences of the translated products showed high homology with GS-1 (Figure 2). Two specific motifs, the double arginine residue (RRX8W) at the N-terminal end and the aspartate rich motif (DDXXD) in the reaction center of the protein [15] [16], were observed in these three clones, and replacement of amino acid residues toward GS-1 was found at only three positions in GS-2, four in GS-3 and eight in GS-4, respectively (Figure 2).

Since nucleotide sequences corresponding to $\mathrm{N}$ - and C-terminal ends of $G S$ - 1 were employed as primers for PCR amplification, 10 and 9 amino acid residues of the terminals remained to be defined. A number of attempts were made to elucidate the undefined translatable and untranslatable regions of these three $\delta$-guaiene synthase genes, and the rapid amplification of cDNA ends method have been systematically performed to obtain the DNA fragments. However, these experiments have not succeeded possibly because only very few nucleotides are replaced in the newly isolated three clones.

\subsection{Preparation and Purification of Recombinant $\delta$-Guaiene Synthase Proteins}

Among seven $\delta$-guaiene synthases reported from Aquilaria [3] [5] [6], six enzyme proteins share the common N-terminal sequence MSSAKLGSAS while remaining one is MSSAKLGSTS (Table 1). On the other hand, C-terminal sequence of all of the seven proteins is identical (ALLRHAIEI). Therefore, we ligated the most probable "missing" amino acid sequences to $\mathrm{N}$ - and C-terminal ends, and catalytic properties of these deficiencies-supplied enzymes (GS-2, GS-3 and GS-4) were examined together with the terminals-lacking translates of $G S-2 \Delta N \Delta C, G S-3 \Delta N \Delta C$ and $G S-4 \Delta N \Delta C$. The recombinant enzymes were obtained as GST-tagged proteins, and were purified by an affinity chromatography on a Glutathione-Sepharose 4B column. In SDS-PAGE analysis (Figure 3), the protein bands corresponding to the position of GST-fused GS-2, 3 and 4 in IPTG-treated cell extracts (approximately $91.5 \mathrm{kDa}$ ) were shown to be sufficiently purified. The recombinant enzymes lacking in the terminal structures were also prepared as GST-tagged forms and purified in a similar manner.

\subsection{Catalytic Activities of Recombinant $\delta$-Guaiene Synthase Proteins}

The recombinant $\delta$-guaiene synthases of $A$. microcarpa were incubated with farnesyl diphosphate, and the reaction products were analyzed by GC-MS. We have previously reported [5] that translate of GS-1 liberates $\delta$-guaiene, $\alpha$-guaiene and germacrene $\mathrm{A}$ as the reaction products. We have also demonstrated [5] that germa- 
GS-1

GS- $2 \Delta N \Delta C$

GS $-3 \Delta N \Delta C$

GS $-4 \Delta N \Delta C$

GS-1

GS $-2 \Delta N \Delta C$

GS $-3 \Delta N \Delta C$

GS $-4 \Delta N \Delta C$

GS-1

GS $-2 \Delta N \Delta C$

GS- $3 \Delta N \Delta C$

GS $-4 \Delta N \Delta C$

GS-1

GS- $2 \Delta N \Delta C$

GS $-3 \Delta N \Delta C$

GS $-4 \Delta N \Delta C$

GS-1

GS $-2 \Delta N \Delta C$

GS $-3 \Delta N \Delta C$

GS $-4 \Delta N \Delta C$

GS-1

GS $-2 \Delta N \Delta C$

GS $-3 \Delta N \Delta C$

GS $-4 \Delta N \Delta C$

GS-1

GS $-2 \Delta N \Delta C$

GS $-3 \Delta N \Delta C$

GS $-4 \Delta N \Delta C$
MSSAKLGSASEDVSRRDANYHPTVWGDFFLTHSSNFLENNHSILEKHEELKOEVRNLLVVETSDLPSKIQLTDKI IRLGV 80 -EDVSRRDADYHPTVWGDFFLTHSSNFLENNHSILEKHEELKQEVRNLLVVETSDLPSK IQLTDKI IRLGV 70 -EDVSRRDANYHPTVWGDFFLTHSSNFLENNDNILEKHEELKQEVTNLLVVETSDLPSK IQLTDE I IRLGV 70 EDVSRRDANYHPTVWGDFFLTHSSNFLENNDNILEKHEELKQEVRNLLVVETSDLPSKIQLTDKI IRLGV 70

GYHFEMEIKAQLEKLHDHQLHLNFDLLTTSVWFRLLRGHGFSISSDVFKRFKNTKGEFETEDARTLWCLYEATHLRVDGE 160 GYHFEMEIKAQLEKLHDHQLHLNFDLLTTSVWFRLLRGHGFSISSDVFKRFKNTKGEFETEDARTSWCLYEATHLRVDGE 150 GYHFEMEIKAQLEKLHDHQLHLNFDLLTTSVWFRLLRGHGFS ISSDVFKRFKNTKGEFETEDARTLWCLYEATHLRVDGE 150 GYHFEME IKAQLEKLHDHQLHLNFDLLTTSVWFRLLRGHGFSISSDVFKRFKNTKGEFETEDARTLWCLYEATHLRVDGE 150

DILEEAIQFSRKKLEALLPELSFPLNECVRDALHIPYHRNVQRLAARQYIPQYDAELTKIESLSLFAKIDFNMLQALHQS 240 DILEEAIQFSRKKLEALLPELSFPLNECVRDALHIPYHRNVQRLAARQY ISQYDAELTKIESLSLFAKIDFNMLQALHQS 230 DILEEAIQFSRKKLEALLPELSFPLNECVRDALHIPYHRNVQRLAARQY IPQYDAELTKIESLSLFAKIDFNMLQALHQS 230 DILEEAIQFSRKKLEALLPELSFPLNECVRDALHIPYHRNVQRLAARQY IPQYDAELTKIESLSLFAKIDFNMLQALHQS 230

ELREASRWWKEFDFPSKLPYARDRIAEGYYWMMGAHFEPKFSLSRKFLNRI I I I TSLIDDTYDVYGTLEEVTLFTEAVER 320 ELREASRWWKEFDFPSKLPYARDRI AEGYYWMMGAHFEPKFSLSRKFLNRI I I ISL I DDTYDVYGTLEEVTLFTEAVER 310 ELREASRWWKEFDFPSKLPYARDRIAEGYYWMMGAHFEPKFSLSRKFLNRI I GI TSL IDDTYDVYGTLEEVTLFTEAVER 310 ELREASRWWKEFDFPSKLPYARDRIAEGYYWMMGAHFEPKFSLSRKFLNRI I I I TSL IDDTYDVYGTLEEVTLFTKAVER 310

WDIEAVKDIPKYMQVIYTGMLGIFEDFKDNL INARGKDYCIDYAIEVFKEIVRSYQREAEYFHTGYVPSYDEYMENSI IS 400 WD IEAVKDIPKYMQVIYTGMLGIFEDFKDNL INARGKDYCIDYAIEVFKEIVRSYQREAEYFHTGYVPSYDEYMENSI IS 390 WDIEAVKDIPKYMQVIYTGMLGIFEDFKDNL INARGKDYCIDYAIEVFKEIVRSYQREAEYFHTGYVPSYDEYMENSI IS 390 WD IEAVQD IPKYMQVIYTGMLGIFEDFKDNLINARGKDYCIDYAIEVFKEIVRSYQREAEYFHTGYVPSYDEYMENSI IS 350

GGYKMF I ILML I GRAEFELKETLDWAST I PEMVKASSL I ARY I DDLQTYKAEEERGETVSAVRCYMREYGVSEEEACKKM 480 GGYKMF I ILML I GRAEFELKETLDWAST I PEMVKASSL I ARYIDDLQTYKAEEERGETVSAVRCYMREYGVSEEEACKKM 470 GGYKMF I ILML I GRAEFELKETLDWAST I PEMVKASSL I ARY IDDLQTYKAEEERGETVSAVRCYMREYGVSEEEACKKM 470 GGYKMF I I LML I GRGEFELKETLDWAST I PEMVKASSL I ARY IDDLQTYKAEEKRGETVSAVRCYMREYGVSEEEACKKM 470

REMIEIEWKRLNKTTLEADEISSSVVIPSLNFTRVLEVMYDKGDGYSDSQGVTKDRIAALLRHAIEI 547 REMIEIEWKRLNKTTLEADE ISSSVVIPSLNFTRVLEVMYDKGDGYSDSQGVTKDRIA---_---- 528 REMIEIEWKRLNKTTLEADEISSSVVIPSLNFTRVLEVMYDKGDGYSDSQGVTKGRIA-------- 528 REMIEI IEWKKLNKTTLEANE ISSSVVIPSLNFTRVLEVMYDKGDGYSDSQGVTKDRIA--------- 528

Figure 2. Alignment of amino acid sequence of $\delta$-guaiene synthases from A. microcarpa. Non-conserved amino acids were shaded, and GenBank accession numbers are as follows; GS-1, KF800046;

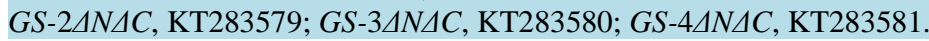

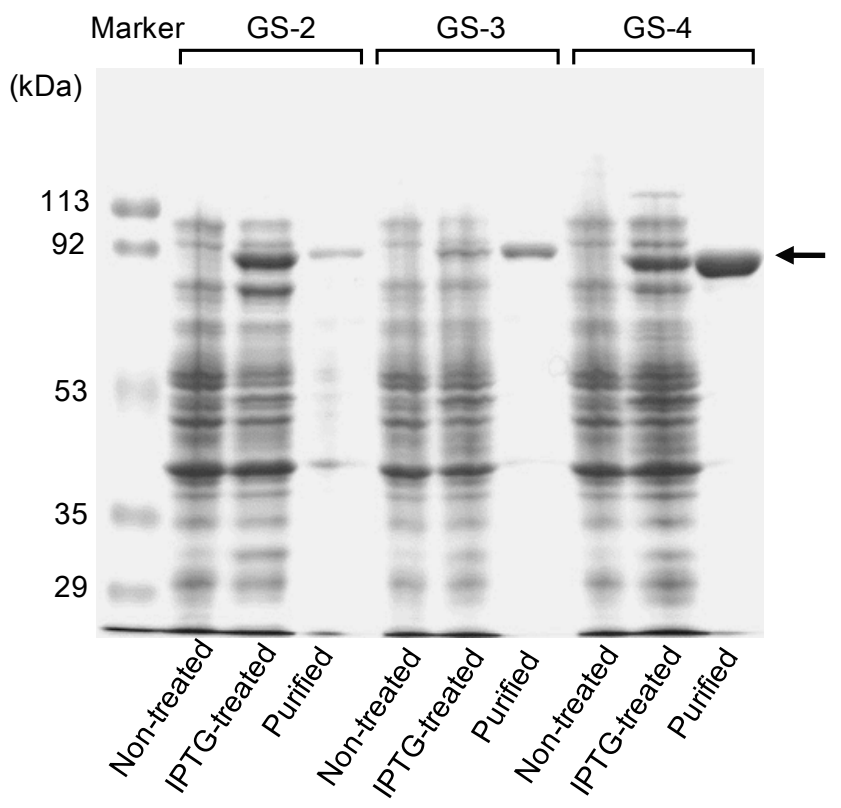

Figure 3. SDS-PAGE analysis of production and purification of $\delta$-guaiene synthase proteins. GS-2, GS-3 and GS-4 were overexpressed in E. coli cells, and the translated products were obtained as GST-fusion proteins. The crude extracts prepared from non-treated control, IPTG-treated cells and the purified proteins were analyzed by SDS-PAGE, and the expected position of GST-fused $\delta$-guaiene synthase (approximately $91.5 \mathrm{kDa}$ ) was indicated by an arrow. 
Table 1. Amino acid sequences of N- and C-terminal ends of $\delta$-guaiene synthases isolated from Aquilaria plants.

\begin{tabular}{ccc}
\hline & N-terminal end & \\
\hline A. microcarpa GS-1 & MSSAKLGSAS & 10 \\
A. sinensis-1 & MSSAKLGSAS & 10 \\
A. sinensis-2 & MSSAKLGSAS & 10 \\
A. sinensis-3 & MSSAKLGSAS & 10 \\
A. crassna-1 & MSSAKLGSAS & 10 \\
A. crassna-2 & MSSAKLGSAS & 10 \\
A. crassna-3 & MSSAKLGSAS & 10 \\
\hline A. microcarpa GS-1 & ALLRHAIEI & 547 \\
A. sinensis-1 & ALLRHAIEI & 547 \\
A. sinensis-2 & ALLRHAIEI & 547 \\
A. sinensis-3 & ALLRHAIEI & 547 \\
A. crassna-1 & ALLRHAIEI & 547 \\
A. crassna-2 & ALLRHAIEI & 547 \\
A. crassna-3 & ALLRHAIEI & 547 \\
\hline
\end{tabular}

GenBank accession numbers are as follows; A. sinensis-1, JQ712682; A. sinensis-2, JQ712683; A. sinensis-3, JQ712684; A. crassna-1, GU083697; A. crassna-2, GU083698; A. crassna-3, GU083699.

crene A is easily converted to $\beta$-elemene by pyrolysis, and, therefore, under the usual GC-MS conditions, together with $\alpha$-and $\delta$-guaiene, $\beta$-elemene was observed as the apparent product of the enzymatic reaction instead of germacrene A. As shown in Figure 4(a), GS-2 produced at least three sesquiterpene compounds, and peak numbers 1,2 and 4 were assigned to be $\beta$-elemene, $\alpha$-guaiene and $\delta$-guaiene by the retention indices and mass spectra (Figure 5) in the data base, respectively [13] [14]. In sharp contrast, detectable amount of the reaction products was not observed when the assay was carried out with the terminals sequences-omitted form, GS-2 $\triangle N \triangle C$ (Figure 4(a)). Heat denatured enzyme proteins also did not show the catalytic activity (data not shown). GS-3 was also capable of producing $\beta$-elemene, $\alpha$-guaiene and $\delta$-guaiene as the major products, however, unlike in GS-1 [5] and GS-2, this protein was found to liberate $\alpha$-humulene (peak 3) as an additional minor product (Figure 4(b) and Figure 5). As well as GS-2 $\triangle N \Delta C$, GS-3 $\triangle N \Delta C$ did not exhibit the sesuqiterpene biosynthetic activity. GS-4 showed the catalytic specificity essentially similar to that of GS-3, and this enzyme produced $\beta$-elemene, $\alpha$-guaiene, $\delta$-guaiene and low amount of $\alpha$-humulene (Figure 4(c) and Figure 5). As was in other $\delta$-guaiene synthases, GS-4ANAC was shown to be an inactive protein. In Figure 4(a), it appeared that a minor peak could be observed at the retention time similar to $\alpha$-humulene (peak 3), and, therefore, we carefully examine the possible formation of this sesquiterpene compound in GS-2-catalyzed reaction. However, based on the mass spectra analysis, it was revealed that the apparent minor peak was due to the formation of unknown compound but not $\alpha$-humulene.

In order to elucidate whether or not both $\mathrm{N}$ - and C-terminal structures of $\delta$-guaiene synthase are essential to exhibit the catalytic activity, 10 amino acid residues at $\mathrm{N}$-terminal or 9 amino acids at C-terminal of the enzyme were selectively omitted, and the catalytic activities of these proteins were examined. In this set of the experiments, GS-4 which showed the highest recovery in the protein purification processes was selected, and N-ter-

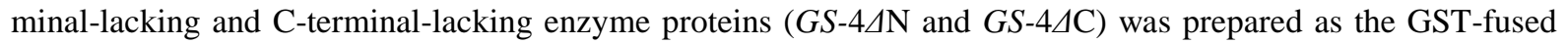
form. As well as GS-4, N-terminal lacking enzyme GS-4AN exhibited the catalytic activity, if somewhat reduced, and the peaks of the sesquiterpene compounds were clearly detected (Figure 6). In sharp contrast, GS-4AC apparently did not show the enzymatic activity, and no peak of the reaction product was observed as far as tested. These results strongly suggest that 9 amino acid residues at C-terminal of $\delta$-guaiene synthase proteins should be an essential structure to function as the sesquiterpene cyclase. 


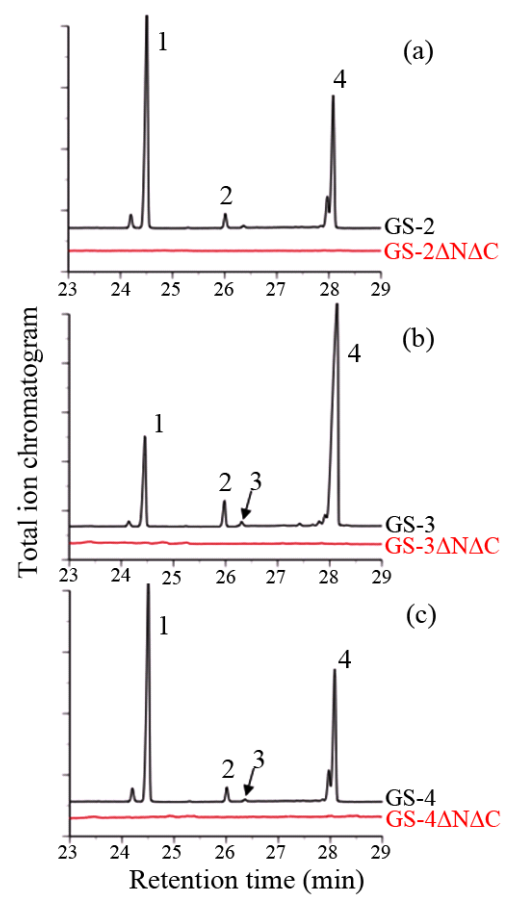

Figure 4. Total ion chromatograms of the reaction products formed by the incubation of recombinant GST- $\delta$-guaiene synthase proteins with farnesyl diphosphate. (a) GS-2

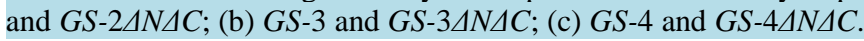

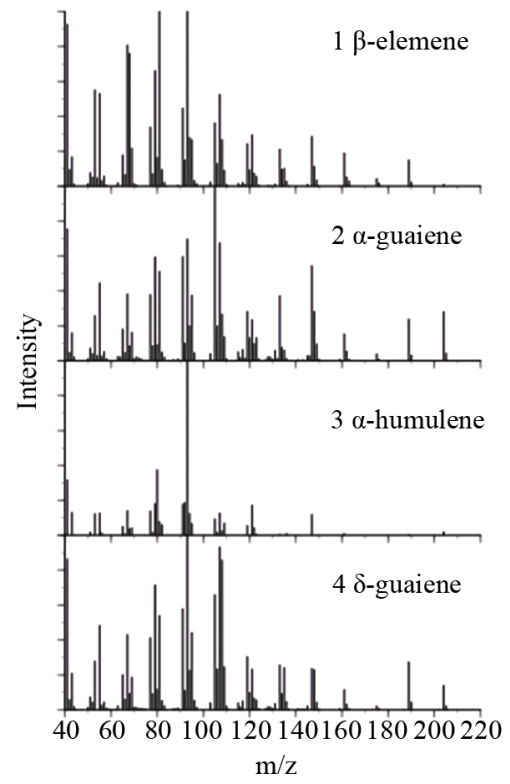

Figure 5. Mass spectra of the compounds corresponding to the peaks shown in Figure 4.

\section{Discussion}

As shown in Figure 1, $\alpha$ - and $\delta$-guaiene are thought to be synthesized from germacrene $\mathrm{A}$ as an intermediate. On the other hand, $\alpha$-humulene biosynthesis shares the common pathway with guaienes-forming processes only in the early stage. Kumeta and Itoh [3] isolated three $\delta$-guaiene synthase genes from A. crassna, and showed that the translated proteins of all of these genes generate $\delta$-guaiene, $\alpha$-guaiene plus $\alpha$-humulene as the minor product. 


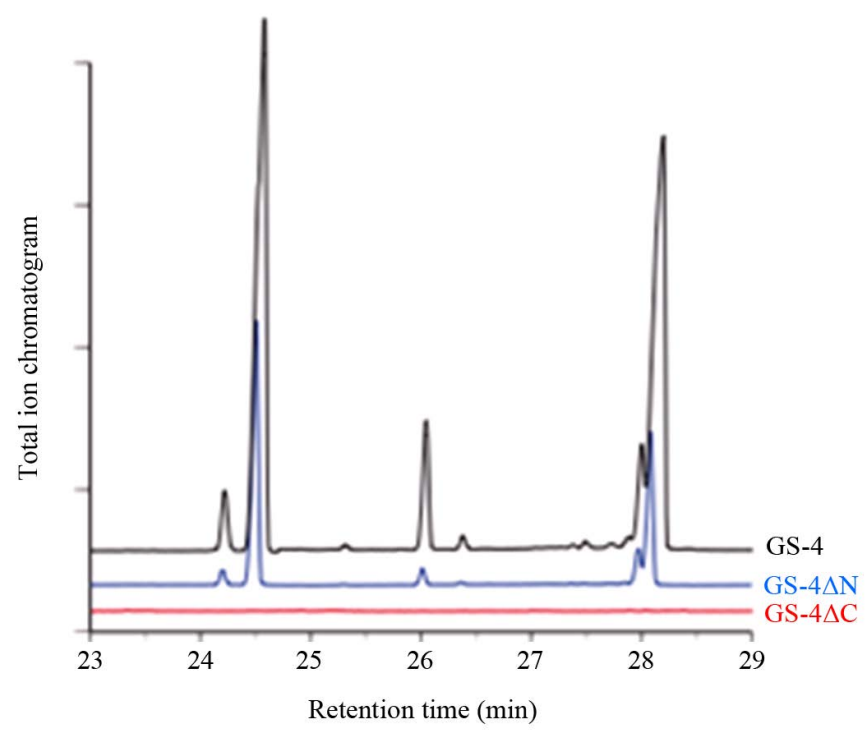

Figure 6. Total ion chromatograms of the reaction products liberated by recombinant $\delta$-guaiene synthases; GS-4, GS-44N and GS-4AC.

In contrast, Xu et al. have recently reported [6] that three homologous genes of $\delta$-guaiene synthase were isolated from $A$. sinensis, and the translated proteins liberate $\delta$-guaiene, $\alpha$-guaiene and $\beta$-elemene but not $\alpha$-humulene. Therefore, it is assumed that two classes of $\delta$-guaiene synthase would occur in Aquilaria plants; $\delta$-guaiene, $\alpha$ guaiene and $\beta$-elemene producing group (A. sinensis), and $\delta$-guaiene, $\alpha$-guaiene and $\alpha$-humulene producing group (A. crassna). We have previously reported [5] that GS-1, the translated product of a $\delta$-guaiene synthase gene isolated from $A$. microcarpa cell culture, is capable of producing $\delta$-guaiene, $\alpha$-guaiene and $\beta$-elemene, however, the formation of $\alpha$-humulene by GS-1 was not observed. In the present experiments, we have isolated three additional cDNA clones encoding the partial structures of $\delta$-guaiene synthase (GS-2 $\triangle N \Delta C, G S-3 \Delta N \Delta C$ and $G S-4 \Delta N \Delta C$ ) from A. microcarpa (Figure 2). We have also shown that the modified proteins, in which probable missing amino acid residues at $\mathrm{N}$ - and C-terminals were supplied (GS-2, GS-3 and GS-4), showed unique catalytic properties (Figure 4 and Figure 5). The reaction products of GS-2 were $\alpha$-guaiene, $\delta$-guaiene and $\beta$-elemene, and liberation of $\alpha$-humulene was not observed. Therefore, catalytic specificity of GS-2 was found to be similar to that of GS-1 isolated from A. microcarpa [5] and three $\delta$-guaiene synthases from A. sinensis [6]. In contrast, GS-3 and GS-4 produced $\alpha$ - and $\delta$-guaiene, $\beta$-elemene plus $\alpha$-humulene, and, therefore, characteristics of the enzyme reaction of GS-3 and GS-4 should resemble the synthases from A. crassna [3]. These observations imply that two classes of $\delta$-guaiene synthase, $\alpha$-humulene producing and non-producing types, would concomitantly occur in A. microcarpa cells. In order to clarify the molecular bases of these unique specificities of $\delta$-guaiene synthases in Aquilaria plants, preparation and characterization of several mutant proteins of the synthase are in progress in our laboratory in which the non-conserved amino acids presented in Figure 2 are appropriately replaced.

Although recombinant GS-2, 3 and 4 proteins showed the biosynthetic activity of the sesquiterpene compounds, N- and C-terminals-deleted proteins, GS-2 $\triangle N \Delta C$, GS-3 $\Delta N \Delta C$ and $G S-4 \Delta N \Delta C$, did not catalyze the terpenoids production (Figure 4). However, GS-4AN, deleted solely N-terminal end, clearly showed the enzymatic activity (Figure 6) while GS-4AC without C-terminal was found to lose the catalytic function. These observations strongly suggest that several amino acid residues at C-terminal end of GS-4 protein are essential to exhibit the terpene cyclase activity. We are attempting to construct the 3D model of the enzyme protein employing the suitable related protein(s) as the template for the elucidation of the biochemical functions of C-terminal amino acid sequence of $\delta$-guaiene synthase.

\section{Acknowledgements}

This work was supported in part by Grant-in-Aid (No. 15K07990 to FK) from the Ministry of Education, Culture, Sports, Science and Technology of Japan, and by funding from Takahashi Industrial and Economic Re- 
search Foundation to FK.

\section{References}

[1] Ng, L.T., Chang, Y.S. and Kadir, A.A. (1997) A Review on Agar (gaharu) Producing Aquilaria Species. Journal of Tropical Forest Products, 2, 272-285.

[2] Okudera, Y. and Ito, M. (2009) Production of Agarwood Fragrant Constituents in Aquilaria Calli and Suspension Cultures. Plant Biotechnology, 26, 307-315. http://dx.doi.org/10.5511/plantbiotechnology.26.307

[3] Kumeta, Y. and Ito, M. (2010) Characterization of $\delta$-Guaiene Synthases from Cultured Cells of Aquilaria Responsible for the Formation of the Sesquiterpenes in Agarwood. Plant Physiology, 154, 1998-2007. http://dx.doi.org/10.1104/pp.110.161828

[4] Kraker, J.W., Franssen, M.C.R., Groot, A., Koenig, W.A. and Bouwmeester, H.J. (1998) (+)-Germacrene A Biosynthesis. The Committed Step in the Biosynthesis of Bitter Sesquiterpene Lactones in Chicory. Plant Physiology, 117, 1381-1392. http://dx.doi.org/10.1104/pp.117.4.1381

[5] Lee, J.B., Hirohashi, S., Yamamura, Y., Taura, F. and Kurosaki, F. (2014) Induction, Cloning and Functional Expression of a Sesquiterpene Biosynthetic Enzyme, $\delta$-Guaiene Synthase, of Aquilaria microcarpa Cell Cultures. Natural Product Communications, 9, 1231-1236.

[6] Xu, Y., Zhang, Z., Wang, M., Wei, J., Chen, H., Gao, Z., Sui, C., Luo, H., Zhang, X., Yang, Y., Meng, H. and Li, W. (2013) Identification of Genes Related to Agarwood Formation: Transcriptome Analysis of Healthy and Wounded Tssues of Aquilaria sinensis. BMC Genomics, 14, 227-242. http://dx.doi.org/10.1186/1471-2164-14-227

[7] Kenmotsu, Y., Ogita, S., Katoh, Y., Yamamura, Y., Takao, Y., Tatsuo, Y., Fujino, H., Kadota, S. and Kurosaki, F. (2011) Methyl Jasmonate-Induced Enhancement of Expression Activity of Am-FaPS-1, a Putative Farnesyl Diphosphate Synthase Gene from Aquilaria microcarpa. Journal of Natural Medicines, 65, 194-197. http://dx.doi.org/10.1007/s11418-010-0451-4

[8] Murashige, T. and Skoog, F. (1962) A Revised Medium for Rapid Growth and Bioassays with Tobacco Tissue Culture. Physiologia Plantarum, 15, 473-479. http://dx.doi.org/10.1111/j.1399-3054.1962.tb08052.x

[9] Kenmotsu, Y., Asano, K., Yamamura, Y. and Kurosaki, F. (2013) Cloning and Expression of Putative Rac/Rop GTPase Genes, Am-rac1 and Am-rac2, Involved in Methyl Jasmonate-Induced Transcriptional Activation of Farnesyl Diphosphate Synthase in Cell Cultures of Aquilaria microcarpa. Plant Molecular Biology Reporter, 31, 539-546. http://dx.doi.org/10.1007/s11105-012-0529-0

[10] Kurosaki, F. and Taura, F. (2015) Transcriptional Activation of Sesquiterpene Biosynthetic Enzyme $\delta$-Guaiene Synthase Gene in Cell Cultures of Aquiralia microcarpa Overexpressing cam 1 and rac2 Encoding Calmodulin and Rac GTPase. Plant Gene, 2, 25-28. http://dx.doi.org/10.1016/j.plgene.2015.03.004

[11] Bradford, M.M. (1976) A Rapid and Sensitive Method for Quantitation of Microgram Quantities of Protein Utilizing the Principle of Protein-Dye Binding. Analytical Biochemistry, 72, 248-254. http://dx.doi.org/10.1016/0003-2697(76)90527-3

[12] Laemmli, U.K. (1970) Cleavage of Structural Proteins during the Assembly of the Head of Bacteriophage T4. Nature, 227, 680-685. http://dx.doi.org/10.1038/227680a0

[13] Babushok, V.I., Linstrom, P.J. and Zenkevich, I.G. (2011) Retention Indices for Frequently Reported Compounds of Plant Essential Oils. Journal of Physical and Chemical Reference Data, 40, Article ID: 043101. http://dx.doi.org/10.1063/1.3653552

[14] Bos, R., Woerdenbag, H.J., Hendriks, H., Smit, H.F., Wikstroem, H.V. and Scheffer, J.J. (1997) Composition of the Essential Oil from Roots and Rhizomes of Valeriana wallichii DC. Flavour and Fragrance Journal, 12, $123-131$. http://dx.doi.org/10.1002/(SICI)1099-1026(199703)12:2<123::AID-FFJ613>3.0.CO;2-4

[15] Bohlmann, J., Meyer-Gauen, G. and Croteau, R. (1998) Plant Terpenoid Synthases: Molecular Biology and Phylogenetic Analysis. Proceedings of the National Academy of Sciences of the United States of America, 95, 4126-4133. http://dx.doi.org/10.1073/pnas.95.8.4126

[16] Whittington, D.A., Wise, M.L., Urbansky, M., Coates, R.M., Croteau, R.B. and Christianson, D.W. (2002) Bornyl Diphosphate Synthase: Structure and Strategy for Carbocation Manipulation by a Terpenoid Cyclase. Proceedings of the National Academy of Sciences of the United States of America, 99, 15375-15380. http://dx.doi.org/10.1073/pnas.232591099 